\title{
Interpretation of trialectic meaning-making strategies
}

\author{
Irina Abakumova ${ }^{1, *}$, Karina Kolesina ${ }^{2}$, Mikhail Godunov ${ }^{3}$ \\ ${ }^{1}$ Don State Technical University, 1, Gagarina Sq., Rostov-on-Don, 344000, Russia \\ ${ }^{2}$ Southern Federal University, Institute of Philology, Journalism and Cross-Cultural Communication, \\ 93, Universitetsky St., Rostov-on-Don, 344006, Russia \\ ${ }^{3}$ Educational and Methodical Center «Tempus», 51, 18 Liniya St., Rostov-on-Don, 344037, Russia
}

\begin{abstract}
Insights into meaning regulation expand, thus making possible to forecast human behavior with greater accuracy. This is of special importance in overcoming crisis situations in a fast-changing society. A meaning-making strategy defines the direction and content of generated meanings, which control human behavior and attitude to what is happening. To develop a meaning psychology, one should improve the well-known simple schemata of dual interpretation of meaning-making strategies. The next, more complex, yet more adequate level of meaning-making interpretation, is the trialectic approach. The authors of this article propose a theoretical justification to the trialectic model of meaning-making strategies. This theoretical model grounds the following triad of meaningmaking strategies: hypoadaptivity strategy, hyperadaptivity strategy and preadaptivity strategy. It permits to better detect the actual human meanings and simulate development of man in today's world. Determination of such peculiarities enables to carry out multi-variant empirical diagnostic of deeds, attitudes, and behavioral responses.
\end{abstract}

\section{Introduction}

Within the framework of the cultural and historical concept, the meaning was initially viewed as a category of psycholinguistics. It predominates over the meaning of the utterance, yet it is of a preverbal nature as an affective attitude to the outer world [1]. The category of attitudes is viewed in Myasishchev's works as a result of mind reflection of the real-world human existence. Meanwhile the formation of personal attributes, which make the moral nucleus, needs special organization of personal attitudes in activity: motivation to cooperation, mutual aid, backing of the activity with positive mutual relations, which incline to moral deeds [2]. L. Vygotsky outlined apposition on the meaning stipulation by the activity motive, which was later confirmed by A. Leontyev [3]. He proved that the attitude of the motive generates the meaning, which, being sent through such a personality attitude to circumstances, turns into a personal meaning. Hence personal meanings possess not just intellectual content, but also deep emotional coloring, emotional experience.

\footnotetext{
*Corresponding author: godunmv997@gmail.com
} 
In our previous investigations of meaning regulation we already analyzed the elementary personological model in terms of dual correlations of personal attributes. Their representation as a bipolar semantic scales ensemble showed two strategies of organization of the meaning sphere: positive development or decay of personality. This approach restricted the whole variety of the ways of personal development to just binary oppositions. However, to reach a more adequate insight into multidimensional meaning reality, this logically primitive dual description needs transition to the next methodological level.

In this article, peculiarities of manifestations of meaning-making strategies are theoretically viewed from trialectic positions. Such a methodological approach permits a multifactorial diagnostic of various states of the meaning sphere of personality to simulate its behavior in diverse life situations. The objective of the article is to theoretically justify the transition from dual to the triad meaning-making strategies model and the description of the same.

\section{Material and methods}

Observance of the holistic view of the human behavior presupposes, in the meaning sphere investigation, a study of underlying inner states (perceived meanings of the reality as personal meanings) in conjunction with the outer manifestations of the personality attributes. Links between inner meanings and outer personality attributes make the cognitive interest with respect to modelling the mutual influence of the personality structure levels in forecasting behavior in reciprocity situations. According to the inward-integral three-level personality model [4], there is a hierarchical system: the worldview nucleus, the inner world axiologicalmeaning sphere, and the outer shell of the expressive-instrumental level reflecting the character, the abilities and the role of the interacting person.

In meaning-making studies, it is not just the meaning plane genesis that is of interest (since personality is not a finished product, but rather a process [5]), but the personality informal description too. An approach of the kind helps to show "a fan of possibilities" as a set of ways in which personality develops through uncovering actual personality attributes. This language description of attributes means a system view upon the problems of personality, since the meaning approach showing the change of dynamics of personality must be complemented with the definition of its actual attributes reflecting the state as a complex profile.

As the character, according to the three-level personality structure (after D. Leont'ev), is a part of personality entering the shell of the outer expressive-instrumental level [4], the notion of the "personality attribute" is wider than the notion of the "character trait". It is known that personality attribute is a distinction, the element of the personality, expressing the essence of outer and inner interactions [5]. On this basis, the outer shell in the personality model under analysis contains those personality attributes manifested by man in different interactions. We will now analyze the relations emerging between the meanings and attributes of personality as mutually causal and characterized by some complementarity. On the one hand, this means that personal attributes reflect only those meanings, which are there in the axiological-meaning sphere and the worldview nucleus of the given personality. On the other hand, personality meanings influence the formation of the peculiarities of interactions and evaluations-attitudes in various situations, which is expressed by appropriate personality attributes as its features. 


\section{Theory}

The study of the influence of meanings upon activity organization and qualitative content raises the questions of defining the ways of organization of the axiological-meaningful sphere and the mechanisms of its transformation in transition to some new conditions or in the choice of other goals. Then the dynamics of the meaning-making processes will show the essence of those processes taking place in both the inner and outer worlds of man, which will help to better forecast human behavior. The activity-meaningful approach of today views making of meanings as their migration, spread from the leading structures of the meaning sphere nucleus to its periphery, i.e. to the particular manifestations in definite life situations through personal attributes manifestation [6]. This means a possibility of not just activation of the sources of situational meanings being causal images of deeds, but also general regulation of person's activity on the basis of an individual world image.

A meaning-making strategy sets the direction and sign of the generated image-meaning. Personality development presupposes development of meaning-making strategies, which serve as a basis for the actualization of a life meaning-making strategy. Meanings, being determining interaction images, make the nucleus of the axiological-meaningful and motivation personality spheres; they direct its activity at each life level as shown above. This makes the following definition possible: a meaning-making strategy is an organized, under the action of motives, demands, aims, experience, subjective relations, way of personality meanings making and development for their content-related and qualitative nature, as well as reflecting the specificity and dynamics of the person's actualization of meanings in definite life situations.

The simulation carried out by us before on the basis of bipolar semantic scales is the starting and most simplified description of personality in terms of the ensemble of its attributes. Such an elementary personological model utilized dual correlations of the personal attributes showing two strategies of organization of the meaning sphere: positive development or decay of personality. This approach restricted all the richness of variants of personality development to binary-type oppositions. It was feasible as the initial step in simulating the meaning regulation, because the revelation of its mechanisms and peculiarities had to be started with simple images. However, a more adequate insight into the multidimensional meaning reality demands that such a logically primitive dual description must be followed by the next methodological level. That is why the binary logic in meaningmaking strategy description may be complemented by trialectic interpretation. This helps to reveal a large number of meaning nuances alongside their specificities manifested as a steady strategy, to demonstrate their dissimilarity and, at the same time, their contingency, likeness in the logic of behavioral manifestations.

Based on the above, for a more complete simulation of the variety of possible strategies, it is expedient to go over to the next, trialectic level of the meaningful system analysis. Philosophy demonstrates rare in stances of application of trialectic systems of various nature in man's description. Aristotelian ethics describes three types of soul inclinations: abundance fault, shortage fault, medium possession virtue [7]. In this approach all three inclinations are considered to be contrary to each other: the 'medium' soul virtues possess abundance of some quality as compared to the fault of its deficiency against the shortage fault. Such a system in fact shows three poles placed upon a single line, where the middle position is taken by virtue as a balanced, neutral state between two other poles. According to Plato, Individual Soul has three abilities: will, affective, and mental, the last one being the primate. Then in ethics this reflects three virtues in the form of manhood, enlightened affects, and wisdom, all united by a single one-piece virtue expressing their balance: justice [8].

The later philosophical tradition knows precedents of use of a triad denoting the triple rhythm in the movement of existence and thinking; this is for example shown in Neo- 
Platonism and German classical idealism. Neo-Platonists, more specifically Proclos, developed a trialectic method to describe three stages (degrees) in the movement of existence: staying within the self as in a unity; setting out of the self (emanation) due to distinction with this self; returning to the self from Anderssein [9]. Hegel's triad lies in the basis of his philosophy of procedurality passing through three stages: thesis, antithesis, and synthesis, resolving their contradiction, exterminating form and changing the content of the process, yet retaining its viable elements in transition to a higher evolutionary stage [10].

It should be noted that the two last approaches reflect the view upon the procedurality of the existent as the succession of stages, however our work focuses at the establishment of correlation between different poles being meaning-making strategies within the personality system structure, which might be reflected through its proper ties manifestation.

Psychological studies of personality apply G. Kelly's [11] triad method of repertory grids based upon personality constructs. This method, using the peculiarities of revealing likeness between two objects and their difference from the third one, permits to develop a scale of subjective values and personal predispositions in various situations. Investigation conducted under D. Leont'ev's guidance, revealed the following three types of personal choice: 1) reactive choice made on the basis of direct preferences in the absence of inner problematization and full-fledge dinner activity, i.e. devoid of meaningfulness under chances; 2) active choice of permanence in which man uses his competences, dispositions, interests to stay within the comfort zone rejecting new possibilities; 3) active choice of obscurity in which man is oriented to new possibilities and realizes his experience as the one demanding new modes of operation, which means preference of risks with vague alternatives [12].

We propose a trialectic approach in studying the semantic organization of the personality properties ensemble. This trialectic approach was stimulated by the following circumstance revealed with in bipolar semantic scales: at times such scales showed side-by-side negative personal attributes, although close semantically, yet demonstrating different levels of evidence, filling of the 'shortage - abundance' type. The interweaved attributes can be "unweaved": a single meaningful "plait" of one pole may fall into two "stretches", or branches. Then the bipolar scale shows the third pole, which becomes the center of the third meaning-making strategy of this given construct. The availability of such logically necessary relations is stipulated by different intensities of opposite meaningful elements, which reflects their quantitative-qualitative correlation.

The first, hypoadaptive meaning-making strategy shows absence or insufficient manifestation of the key attribute in the given meaningful dipole. This reflects weak adaptive capacities in situational interactions, manifested as passive adaptation of a reactive choice type for the retention of the available preferences. This is manifested as absence or fragmentarity of a meaningful approach in activities and in taking decisions. A reactive position of the type reflects in sufficient work in the inner world for adequate assessment of the reality and full-fledged integration in the outer world processes. The major attribute of this strategy is juvenilism of personal attributes. This may show as infantilism in the form of retention and dominance of the set of attributes peculiar to the personality at its earlier development stages.

Basically infantilism like "fixedness" at earlier socialization stages is manifested as inability or unwillingness to make well-thought-out timely decisions. An infantile person is only focused on himself, he does not develop as a personality, self-analysis is unfamiliar to him. Such people often fail to understand the others, they do not share other world views and practically ignore other people's interests in their behavior. The basic features of psychological infantilism are dependency and problem avoidance; lack of life goals and strives; unwillingness to develop; inadequate reactions to what is happening; selfishness and irresponsibility; excessive passion for games, gadgets, shopping; inability to communicate; 
superficial mind; sedentary lifestyle [13]. Such world view peculiarities shape corresponding personal meanings, which like causal images determine man's life. "Adult child's" immaturity is often manifested as inability or unwillingness take the responsibility for his life, also named externality. This means orientation to the outer locus of one life control, when all significant events and operating results scarcely depend on one's own activity. A man with this low level of subjective control is confident that his success and failures are only a result of external forces: lick, chances, pressure of the environment and other people [14].

The second, hyperadaptive meaning-making strategy shows abundance of the key personal attribute and is oriented to man's active adaptation. This adaptation type is manifested as person's strive to ignore the inevitable life changes and stay within the comfort zone. To constantly maintain this state of permanence, man utilizes all available resources. Over developing is the key personal attribute in this strategy. The pole of hyperadaptivity reflects the process of excessive personalization, when man applies to himself somebody's roles, masks, which he thinks to be acceptable. This means self-preoccupation, the major criterion now is commensuration with others and personal interest, yet not the customary norm, which is outraged. This type of self-steering and want to seem, yet not be a personality, is viewed as man's desocialization as his delearning [15]. Overdeveloping, overwork and satiety in hyperadaptivity as a form of social experience can be manifested in super controlling both "my own" and other interactions. Mental control of situations and "paternalism" not only lead to obtrusion of an alien will to the participants, they also violate the freedom of their activities, restraining the development of both the personality and the group. The state of overdeveloping as over-the-topness often results in an excessive set of material benefits and appearances of progress.

In a frustration situation, in which the man facing an obstacle cannot gain his objects or satisfy his want, the hyperadaptive personality often demonstrates irritation, aggression. Negative emotions are shown concerning the prevailing situation and its reasons. Surrounding persons are blamed, instructed, made fun of, or stimulated to activities; meanwhile these are the only people who are expected to work out a solution to the problems. In Rosenzweig's theory of frustrational tolerance this shows extrapunitive reactions reflecting an obstacle-dominant type of interaction as a destructive type in an abnormal situation [16].

Availability of the hyperadaptive strategy shows unwillingness to expand the experience, while developing man in the constantly changing world must face the temptation of overdevelopment and get rid of corresponding illusions. Absence of such inner work leads to the formation of corresponding negative causal images blocking the direction of personal advancement and orienting to horizontal movement, i.e. monotonous development in selfsimilar forms.

Between them, these two adaptive strategies have a neutral state reflecting identical correlation of polar meanings transmitted by personality key attributes. This balance is the interposition between the two ways of meaning-making in which equal probability selection (bifurcation) is possible.

The third, preadaptive meaning-making strategy starts at a neutral point and opens the direction of a paradoxical approach to interaction in various situations. Being an off-balance third attractor, it shows direction of an unobvious, yet possible personality development with a number of alternatives. The preadaptive strategy shows availability of such a positive key personality attribute, which helps to perform additional functions or successfully interact in future in both crisis and indefinite situations. The over-situational character of this strategy means manifestation of personal activity for variable adaptation of behavioral schemata, which means their anticipating nature. The conjoined restructuring of the meaningful sphere speaks for its self-cultivation as spiritual growth. 
The two above adaptive strategies emanate from predetermination of goals and ambientdetermined norm of situational activity, and they reflect the availability of a rigid cause-andeffect relationship between man's life attitudes and behavior realizing these. To overcome such adaptability limits it would be wise to mention the person's above-situational activity, i.e. preadaptability [17]. In a state like this active causal links may turn into less strict living conditions since development variability appears. In personality improvement, rigid reasons of its life sustenance giving rise to the necessity to implement direct consequences are replaced by pre-requisites, which form a possibility to actualize their development.

A preadaptive personality has rather an inner than an outer locus of control of its life development, or internality, i.e. it takes life responsibility explaining the goings-on by the peculiarities of its own character, behavior, abilities, skill in building relationships [14]. When a man of this kind finds himself in frustration situations, the dominant reacting type is urgent-persisting, for example fixation on the situation settlement in different ways: through own resources, with the help of other people or by natural passage of events, which seems to be constructive [16]. Attributes of preadaptive personality in present-time situations may seem excessive and unnecessary at first sight. However, in future situations and under new conditions these are preadaptive personality attributes that enable to overcome crisis states of both the outer and inner orders. Availability of tolerance to uncertainty reflects an important attribute of the I-concept: personal growth as a cognitive search and actualization of the top meaning of life. In case there is such implementation, shown is self-transcendence as a true spiritual transformation of man meaning overrunning one's own practical phenominal existence on the way to suprapersonal goals, top meaning of life and its achievement [18].

D. Leont'ev in his study of human behavior proposes, in addition to traditional psychology with an emphasis on the necessity and determinacy (something that cannot be absent), pointing out the "second" psychology accenting possibilities and self-determination, which are not generated by strict cause-and-effect relationships, yet can exist. Meanwhile the locus of man, apart from sub-human, low-cost existence, may have a true human, autonomous development level to orient behavior in the space of the possible, which is paradoxical to everyday life determinacy [19]. A nonlinear transfer from the necessity to "a fan of possibilities" is a paradoxical deed of synergetic nature, which is not feasible in the terms of the lowest biological regulators, yet unique and sensible in the terms of supreme values.

Since the essence of self-transcendence is a search for the meaning of life as the higher purpose and its actualization, application of paradoxical logic in habitual situations is possible if man is aware of the higher ways. A search for predestination is a great risk, the most difficult labor, which may nor lead to an automatic success [20]. In one of his later interviews A. Maslow said that he had failed to empirically prove his thesis about the satisfaction of the human basic needs as the explicit reason, which inevitably and expressly spawns personality transition to self-actualization. He stated that after reaching the level where the basic needs are not critical for life activity, one part of people move on towards self-actualization, while the others stop [21]. As long as man is in search of himself, he is looking through his abilities being unable to sense his solvency and maturity; when man enters the new he is with little protection in his creation, being vulnerable in comparison with those who stay within the comfort zone.

\section{Results}

We propose the following definitions to trialectic meaning-making strategies.

1) Hypoadaptive meaning-making strategy is a way of organizing the meaningful sphere, supported by formal preferences, focused on passive joining and driven movement within the 
layer of those personal meanings dictated by the overwhelming life circumstances without their actual realization.

2) Hyperadaptive meaning- making strategy is a way of organizing the meaningful sphere, based on an actual experience and stereotyped predetermination of the achieved goals, focused on retaining the unchanged contents of personal meanings through the application of all the available resources and rejection of the new possibilities for meaningful sphere development.

3) Preadaptive meaning-making strategy is a way of organizing the meaningful sphere, oriented to the realization of motives and generation of essential goals, focused on shaping challenging personal meanings and their timely transformation in order to fulfill the possibility of spiritual growth under inner and outer circumstances evaluated as superable life situations provided there is individual's self-determination of his own activity.

\section{Discussion}

The three proposed strategies stipulating the direction and quality contents of new meanings, actualize essentially different approaches to interaction within situations. Hypoadaptive and hyperadaptive strategies include new information in the available schemata and further schematic activity with new objects on the basis of the already shaped skills. In preadaptive strategy behavioral schemes are variably adjusted to the new situations, which demand definite activity, over-situational too, which means its anticipative character.

\section{Conclusions}

The shown trialectic approach to the study of meaning-making strategies may be used to reveal the trialectic organization of the personal attributes as a whole. In our further investigation we are planning to empirically study the peculiarities of the proposed meaningmaking strategies, with semantic trialectic scales developed for them. Tests with the use of the above will be conducted with a number of time-tried methods in order to reveal the peculiarities of meaningful regulation. Application of such a trialectic instrument permits to find triads of key personal attributes and their correlation with other criteria of the meaningful sphere development. This may serve as a basis for working out a personality profile being a multi-factor model for the possible states in the axiological-meaningful sphere of the angstridden person. In what concerns behavior simulation as one of the major problems in psychology, a personality profile of the kind shows the direction and quality peculiarities of meaningful regulation as it reflects the real working strategy of formation of meanings as polimodal causal images.

\section{Acknowledgements}

This investigation has been carried out under RFFI Grant18-29-22004 (2018): "Psychological and genetic studies of the predictors determining users' behavior in their perception of web contents of various informative targeting".

\section{References}

1. L.S. Vygotsky, The pedagogical seminary and journal of genetic psychology 36(3), 415434 (1929) https://doi.org/10.1080/08856559.1929.10532201 
2. V.N. Myasishchev, Struktura lichnosti $i$ otnoshenie cheloveka $k$ deystvitel'nosti. Psikhologiya lichnosti (Bakhrakh-M., Samara, 2013)

3. A.N. Leont'ev, Deyatelnost $i$ soznanie. Obschaya teoriya smysla, psikhologicheskie kontseptsii smysloobrazovaniya, smyslodidaktika (Kredo, Moscow, 2014)

4. D.A. Leont'ev, Ocherk psikhologii lichnosti (Smysl, Moscow, 1997)

5. G.W. Allport, The Journal of Abnormal and Social Psychology 61(3), 301-310 (1960) https://content.apa.org/doi/10.1037/h0043619

6. D.A. Leont'ev, Psikhologiya smysla: priroda, stroenie i dinamika smyslovoy real'nosti (Smysl, Moscow, 2007)

7. Aristotle: Oxford Classical Texts: Aristotelis: Ethica Eudemia (Oxford University Press, 1991) https://doi.org/10.1093/actrade/9780198145752.book.1

8. Plato: Dialogi (Eksmo, Moscow, 2016)

9. Proclos: Commentary on Plato's Parmenides (Princeton University Press, Princeton, NJ, USA, 2017)

10. G.W.F. Hegel, Vvedenie v filosofiyu. Filosofskaya propedevtika (Seriya: Iz naslediya mirovoy filosofskoy mysli. Istoriya filosofii) (Librokom, Moscow, 2018)

11. G. Kelly, The psychology of personal constructs (Routledge, L., 2020) https://doi.org/10.4324/9780203359037

12. Ye.Yu. Mandrikova, Vidy lichnostnogo vybora i ikh individual'no-psikhologicheskie predposylki: diss. ... kand. psikhol. nauk (MGU, Moscow, 2006)

13. N.A. Zhestkova, Vestnik Permskogo universiteta. Filosofiya. Sociologiya. Psikhologiya 2(14), 128-136 (2013)

14. G.I. Oshchepkova, Filologiya i kul'tura 3(41), 333-337 (2015)

15. O.V. Ivanovskaya, Nauchnye problemy gumanitarnykh issledovaniy 1, 256-268 (2010)

16. S. Rosenzweig, Journal of Personality 14(1), 3-23 (1945) https://doi.org/10.1111/j.14676494.1945.tb01036.x

17. V.A. Petrovskiy, Lichnost' kak subyekt aktivnosti Psikhologiya lichnosti (Bakhrakh-M., Samara, 2013)

18. V.E. Frankl, The Doctor and the Soul (Vintage Books, N.Y., 1973)

19. D.A. Leont'ev, Cultural-Historical Psychology 16(2), 19-24 (2020) https://doi.org/10.17759/chp.2020160203

20. A. Adler, Über individualpsychologische Erziehung. Praxis und Theorie der Individualpsychologie (1924) https://doi.org/10.1007/978-3-662-34418-7_27

21. W. Frick, Journal of Humanistic Psychology 40(2), 128-147 (2000) https://doi.org/10.1177/0022167800402003 